\title{
172 IL-1 BETA SECRETION IN CORONARY VASCULAR ENDOTHELIUM IS MEDIATED BY NEUTROPHIL SERINE PROTEASE AND IS INDEPENDENT OF CASPASE-1.
}

M Alfaidi, H Wilson, A Burnett, J Chamberlain, S Francis University of Sheffield

doi:10.1136/heartjnl-2013-304019.172

Introduction Atherosclerosis is characterized by endothelial dysfunction, massive inflammatory cell recruitment and activation of leukocytes, accompanied by extracellular release of interleukin-1 beta (IL-1 $\beta$ ), a potent pro-inflammatory mediator with proatherogenic effects. Even though IL-1 $\beta$ has been clearly implicated in atherogenesis, potentially via its secretion from activated endothelial cells (ECs), its mechanism of release remains unknown. The proximity of immune cells, monocytes and neutrophils to endothelium during plaque formation and rupture makes it likely that cross talk between cell types and release of soluble factors could cause IL-1 release from endothelial cells. Therefore, we hypothesised that a serine protease called neutrophil elastase (NE), produced by circulating inflammatory cells, might modulate IL-1 release from endothelial cells.

Methods Human coronary artery endothelial cells (HCAEC) were treated with a combination of tumour necrosis factor-alpha (TNF- $\alpha$; $10 \mathrm{ng} / \mathrm{ml}$ ) and interleukin-1 alpha (IL-1- $\alpha ; 10 \mathrm{ng} / \mathrm{ml}$ ) for 48 hours to up-regulate intracellular IL-1 $\beta$. The cells were then incubated with $\mathrm{NE}(1 \mu \mathrm{g} / \mathrm{ml})$ for 2 or 6 hours in serum-free media. ELISA, western blotting, flow cytometry and live cell imaging were used to determine IL-1 $\beta$ expression, cellular changes and a potential mechanism.

Results NE caused significant IL- $1 \beta$ release into supernatants after $6 \mathrm{~h}$ $(579 \pm 90$ versus $80 \pm 19 \mathrm{pg} / \mathrm{ml}$ in control; $\mathrm{n}=4, \quad p<0.0001)$. Pre-treatment of cells for $30 \mathrm{~min}$ with neutrophil elastase inhibitor type III (NEIII, $500 \mu \mathrm{M}$ ) significantly decreased IL-1 $\beta$ release (62.64 \pm 10 versus $579.3 \pm 90 \mathrm{pg} / \mathrm{ml}$ in primed cells; $\mathrm{n}=3, p<0.05$ ); but, the levels of IL-1 $\beta$ in the supernatant or lysate did not change in the presence of caspase- 1 inhibitor (Ac-YVAD-CHO, $5 \mu \mathrm{M}$ ). Cell lysates contained the inactive, usually referred to as proform of IL- $1 \beta$ and supernatants contained pro and active IL-1 $\beta$ isoforms. Release and cleavage of IL- $1 \beta$ was independent of caspase- 1 activity. Live cell imaging revealed that HCAEC shed microvesicles from their plasma membranes after NE stimulation and that these released microvesicles contained IL-1 $\beta$.

Conclusions This is the first description of the release of IL-1 $\beta$ from HCAEC. This is associated with EC microvesicle formation, and the release occurs via a caspase- 1 independent mechanism. Neutrophil elastase has been detected in diseased human coronary arteries and, therefore, this is a plausible mechanism to promote local IL-1 $\beta$ release in the vessel wall. 